\title{
What is the evidence of a role for host genetics in susceptibility to influenza $\mathrm{A} / \mathrm{H} 5 \mathrm{~N} 1$ ?
}

\author{
P. HORBY ${ }^{1,2 *}$, H. SUDOYO ${ }^{3}$, V. VIPRAKASIT ${ }^{4}$, A. FOX ${ }^{1,2}$, P. Q. THAI ${ }^{5}, \mathrm{H}^{2} \mathrm{YU}^{6}$, \\ S. DAVILA ${ }^{7}$, M. HIBBERD ${ }^{7}$, S. J. DUNSTAN ${ }^{1,2}$, Y. MONTEERARAT ${ }^{4}$, \\ J. J. FARRAR ${ }^{1,2}$, S. MARZUKI ${ }^{3}$ AND N. T. HIEN ${ }^{5}$ \\ ${ }^{1}$ Oxford University Clinical Research Unit, Vietnam \\ ${ }^{2}$ Centre for Tropical Medicine, Nuffield Department of Clinical Medicine, Oxford University, UK \\ ${ }^{3}$ Eijkman Institute for Molecular Biology, Jakarta, Indonesia \\ ${ }^{4}$ Department of Pediatrics, Faculty of Medicine Siriraj Hospital, Mahidol University, Bangkok \\ ${ }^{5}$ National Institute for Hygiene and Epidemiology, Hanoi, Vietnam \\ ${ }^{6}$ Chinese Centre for Disease Control and Prevention, Beijing, People's Republic of China \\ ${ }^{7}$ Genome Institute of Singapore, Genome Building, Singapore
}

(Accepted 10 February 2010; first published online 18 March 2010)

\section{SUMMARY}

The apparent family clustering of avian influenza A/H5N1 has led several groups to postulate the existence of a host genetic influence on susceptibility to $\mathrm{A} / \mathrm{H} 5 \mathrm{~N} 1$, yet the role of host factors on the risk of $\mathrm{A} / \mathrm{H} 5 \mathrm{~N} 1$ disease has received remarkably little attention compared to the efforts focused on viral factors. We examined the epidemiological patterns of human $\mathrm{A} / \mathrm{H} 5 \mathrm{~N} 1$ cases, their possible explanations, and the plausibility of a host genetic effect on susceptibility to A/H5N1 infection. The preponderance of familial clustering of cases and the relative lack of non-familial clusters, the occurrence of related cases separated by time and place, and the paucity of cases in some highly exposed groups such as poultry cullers, are consistent with a host genetic effect. Animal models support the biological plausibility of genetic susceptibility to A/H5N1. Although the evidence is circumstantial, host genetic factors are a parsimonious explanation for the unusual epidemiology of human A/H5N1 cases and warrant further investigation.

Key words: Influenza A virus, genetic susceptibility, H5N1 subtype.

\section{INTRODUCTION}

Human cases of influenza A subtype H5N1 appear to cluster in families, a pattern which has led several authors to comment that host genetics may play an important role in susceptibility to A/H5N1 infection

* Author for correspondence: Dr P. Horby, Centre for Tropical Medicine, Nuffield Department of Clinical Medicine, Oxford University, Oxford OX3 7LJ, UK.

(Email: peter.horby@gmail.com) or disease [1-5]. This has potentially far-reaching implications, since the identification and subsequent characterization of genetic factors that have a strong influence on susceptibility to A/H5N1 disease would highlight key virus-host interactions necessary or contributory to infection or disease. Elucidating these key interactions has the potential to catalyse advances in areas such as the prediction of viral pathogenicity and the development of new or improved preventive and therapeutic interventions, which may be of 
Table 1. Number of confirmed H5N1 cases and clusters by country

\begin{tabular}{lccc}
\hline \hline & $\begin{array}{l}\text { Total } \\
\text { laboratory-confirmed } \\
\text { cases* }\end{array}$ & $\begin{array}{l}\text { No. of } \\
\text { clusters } \dagger\end{array}$ & $\begin{array}{l}n / N(\%) \text { of } \\
\text { confirmed cases } \\
\text { occurring in } \\
\text { clusters }\end{array}$ \\
Country & 8 & 2 & $6 / 8(75)$ \\
Azerbaijan & 1 & 0 & $0 / 1(0)$ \\
Bangladesh & 8 & 1 & $1 / 8(12)$ \\
Cambodia & 38 & 4 & $4 / 38(10)$ \\
China, mainland & 1 & 0 & $0 / 1(0)$ \\
Djibouti & 88 & 4 & $9 / 88(10)$ \\
Egypt & 20 & 2 & $4 / 20(20)$ \\
China, Hong Kong & 141 & 18 & $36 / 141(25)$ \\
Indonesia & 3 & 1 & $2 / 3(67)$ \\
Iraq & 2 & 0 & $0 / 2(0)$ \\
Laos PDR & 1 & 0 & $0 / 1(0)$ \\
Myanmar & 1 & 1 & $1 / 1(100)$ \\
Nigeria & 3 & 1 & $3 / 3(100)$ \\
Pakistan & 25 & 3 & $5 / 25(20)$ \\
Thailand & 12 & 2 & $6 / 12(50)$ \\
Turkey & 11 & 13 & $26 / 111(23)$ \\
Vietnam & 463 & 52 & $103 / 463(22)$ \\
Total (all countries) & & & \\
\hline \hline
\end{tabular}

* As of 25 November 2009.

$\dagger$ A cluster is defined as at least two cases of clinically compatible illness with at least one case with laboratory-confirmed H5N1.

relevance not only to zoonotic influenza but also to seasonal and pandemic influenza.

Since it re-emerged in $2003 \mathrm{~A} / \mathrm{H} 5 \mathrm{N1}$ has received enormous attention, including the allocation of substantial financial resources for vaccine development and pandemic preparedness. Yet the reasons for its scarcity in humans, its poor ability to transmit between people, the clustering of cases and the risk factors for infection remain elusive; as does our ability to predict the likelihood that A/H5N1 may become a pandemic virus. Most research has focused on the viruses; through genotypic and phenotypic analysis and animal experiments using modified viruses, but the other half of the equation, the host, has been relatively neglected. Since it is epidemiological patterns that have stimulated consideration of host genetic factors, an important first step is to review whether the epidemiological patterns are consistent with a host genetic influence. Currently only two publications have explicitly examined the potential role of host genetics and human A/H5N1 infection. Pitzer et al. have looked at whether the observed clustering could be explained by chance alone [6]. Trammell \& Toth have reviewed possible biological mechanisms of host susceptibility to influenza, using mostly data from murine models [7]. We examine the epidemiological patterns of human $\mathrm{A} / \mathrm{H} 5 \mathrm{~N} 1$ cases, their possible explanations, and review the evidence for a role for host genetics in susceptibility to influenza A/H5N1.

\section{THE CASE IN FAVOUR OF A ROLE FOR HOST GENETICS}

\section{Familial aggregation of cases}

Between 1 January 1997 and 25 November 2009 a total of 36 clusters of two or more laboratoryconfirmed cases of $\mathrm{A} / \mathrm{H} 5 \mathrm{~N} 1$ have been reported, with at least an additional 16 clusters of one confirmed case plus at least one probable case [3, 4, 8-11] (Table 1). These 52 clusters account for $22 \%(103 / 463)$ of all laboratory-confirmed cases and only six of the 103 cases occurring in clusters did not have a genetic relationship to another case in the cluster. Although there is no data on the familial aggregation of other zoonosis for comparison, this degree of family clustering has surprised many people, especially since $\mathrm{A} / \mathrm{H} 5 \mathrm{~N} 1$ is considered to only rarely transmit from person to person. Since familial aggregation is a hallmark of genetically determined diseases, genetic susceptibility to $\mathrm{A} / \mathrm{H} 5 \mathrm{~N} 1$ infection is one hypothesis 
that might explain the familial aggregation. Unfortunately the apparent increased risk in relatives of affected cases compared to background risk has not been quantified and the large cluster in Karo, Indonesia was a missed opportunity to estimate the familial relative risk by comparing the risk in related and unrelated contacts of infected individuals. However, what we do know is that this cluster involved eight cases (seven laboratory-confirmed) in a single extended family residing in four households [12]. Nine family members slept in the same room as the primary case while the case was symptomatic and three of these nine (33\%) developed $\mathrm{A} / \mathrm{H} 5 \mathrm{~N} 1$ infection [13]. It is perhaps surprising that there were no unrelated cases despite multiple opportunities for infection of non-related contacts, including unprotected healthcare workers, and onset dates that stretched over a period of 3 weeks [14].

\section{The relative absence of non-familial aggregation of cases}

If all members of a community affected by $\mathrm{A} / \mathrm{H} 5 \mathrm{~N} 1$ outbreaks in poultry are at equal risk then it would be more likely to observe pairs of cases of unrelated community members than to see household clusters [6]. Yet of the 103 confirmed cases occurring in 52 clusters, only six cases occurring in four clusters were not genetically related to any other case in the cluster [one husband and wife pair (Vietnam 2005); one healthcare worker (Vietnam 2005); one neighbour (Azerbaijan 2006); two children (Egypt 2009)] [11]. This pattern is important since it suggests either large differences in risk between families within affected communities, or large biases in the detection and reporting of family-based clusters compared to unrelated case clusters.

\section{Related but unassociated cases}

At least two incidents have occurred where genetically related individuals developed confirmed or probable $\mathrm{A} / \mathrm{H} 5 \mathrm{~N} 1$ disease independently of one another.

In August 2004 a 25-year-old women from Hau Giang Province, southern Vietnam died from laboratory-confirmed A/H5N1. Both the 19-year-old brother of this case and their 23-year-old cousin died of severe pneumonia within a week of the confirmed case; specimens from these two cases were not tested for $\mathrm{A} / \mathrm{H} 5 \mathrm{~N} 1$. The brother lived with the confirmed case but the cousin lived in a non-adjacent commune

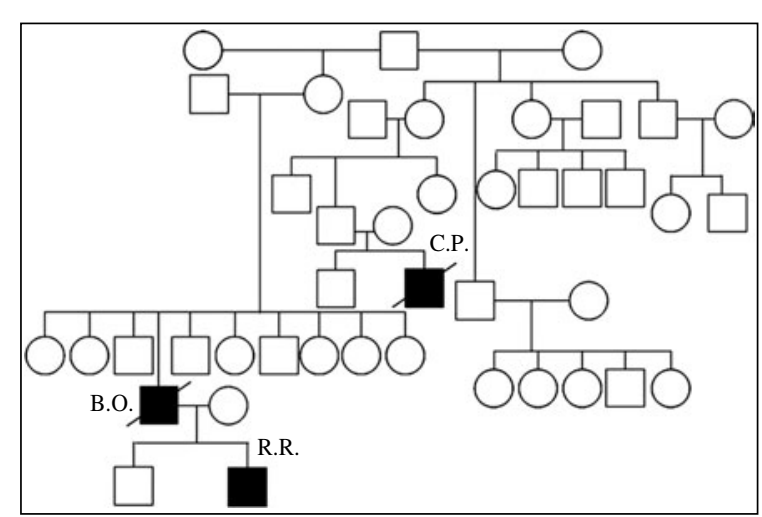

Fig. 1. Family pedigree showing three H5N1 affected individuals, with infections separated by 2 years.

and investigations revealed that there had been no contact whatsoever between the cousin (and her immediate family) and the siblings (and their immediate family) in the week prior to the earliest onset of illness and the deaths. Local authorities concluded that there was no likelihood of a common point source of infection or of any other means of transmission of $\mathrm{A} / \mathrm{H} 5 \mathrm{~N} 1$ between the cousin and the sibling cases. Therefore, the disease in the cousin seems to have occurred independently from the sibling cases.

In Thailand three related individuals suffered $\mathrm{A} / \mathrm{H} 5 \mathrm{~N} 1$ infection during two different waves of the outbreak. The first case was a boy (C.P.) who died during the first wave of outbreaks in late 2003-2004 [15]. The mother of case C.P. also died of a respiratory illness at the same time as her son, but samples were not available for testing for $\mathrm{A} / \mathrm{H} 5 \mathrm{~N} 1$ [8]. The other two cases, a father and son (B.O and R.R.), were infected in the 2005 outbreak [16]. Their family pedigree is shown in Figure 1. C.P. lived in the same province but a different district to B.O. and R.R.

Given the scarcity of $\mathrm{A} / \mathrm{H} 5 \mathrm{~N} 1$ disease, these incidents of related but apparently unconnected cases seem an improbable misfortune, unless relatives have an increased risk of $\mathrm{A} / \mathrm{H} 5 \mathrm{~N} 1$ infection compared to the general population.

\section{Exposure and risk are not well correlated}

Although data from three case-control studies show that contact with dead or dying poultry is a significant risk factor for $\mathrm{A} / \mathrm{H} 5 \mathrm{~N} 1$ infection, the proportion of cases that can be attributed to this factor is not high [17-19]. About $25 \%$ of all confirmed clinical cases of H5N1 infection cannot recall any recent poultry exposure before illness onset and in many other cases 
the reported exposure to infected poultry is tenuous [17, 20-22]. The largest case-control study published so far found that only $28 \%$ of all cases could be attributed to preparing or cooking sick poultry [17]. The same study found no differences between affected and unaffected households in other poultry-handling practices, hygiene behaviour or in other putative risk factors such as the use of poultry fertilizer. This absence of obvious risky practices in many affected individuals and families juxtaposes starkly with the almost complete absence of clinical cases in groups who are known to have engaged in theoretically very high-risk behaviours, i.e. culling infected poultry flocks without personal protective equipment.

From 2003 to 31 January 2010, 49 countries have reported over 6660 outbreaks of highly pathogenic avian influenza $\mathrm{A} / \mathrm{H} 5 \mathrm{~N} 1$ in domestic poultry or wildlife to the World Organization for Animal Health and several hundred million poultry have died or been culled. These figures are a minimum, since only a proportion of all outbreaks are detected and reported. The number of people exposed to $\mathrm{A} / \mathrm{H} 5 \mathrm{~N} 1$ as a result of reported and unreported outbreaks is not known but we do know that exposure to poultry is very common in many of the worst affected countries. One population-based study of more than 45000 people in an $\mathrm{A} / \mathrm{H} 5 \mathrm{~N} 1$-affected community in Vietnam found that $25.9 \%$ (11 755) lived in households where poultry were sick or had died [23]. A community survey in Cambodia of 155 poultry-raising households in an A/H5N1-affected area identified poultry deaths in 102 households $(66 \%)$, and 42 households $(27 \%)$ were considered likely to have experienced an outbreak of A/H5N1 [19]. A larger survey in Cambodia estimated that most of the rural population has frequent contact with poultry and $52 \%$ regularly have a potentially high-risk exposure [1]. Therefore it likely that very large numbers of people, possibly millions, have been exposed to A/H5N1 since 2003 yet only 471 human cases have been reported globally over the same period. It can be safely assumed that these numbers, like poultry outbreaks, are a minimum as the clinical presentation is non-specific and few sites possess the capabilities to diagnose A/H5N1. Although a survey in two affected villages in Cambodia found serological evidence of subclinical A/H5N1 infection in seven ( $1 \%$ ) out of 674 subjects [24], evidence from active surveillance and serological surveys of populations known to be exposed to $\mathrm{A} / \mathrm{H} 5 \mathrm{~N} 1$ generally indicates that large numbers of cases are not being missed [19, 21, 25-33]. While the sensitivity and reproducibility of serological assays for $\mathrm{A} / \mathrm{H} 5 \mathrm{~N} 1$ infection is variable, many serological studies have used the gold standard of microneutralization assay with Western blot confirmation and therefore provide the best estimate currently available of $\mathrm{A} / \mathrm{H} 5 \mathrm{~N} 1$ infection prevalence $[34,35]$. The apparent low incidence of infection following exposure to sick poultry and the low risk in some intensely exposed groups indicates a substantial species barrier, but a barrier that seems to be much weaker in a small number of individuals and families [36].

\section{Person-to-person transmission}

Families live together in intimate contact and personto-person transmission has been convincingly put forward as an explanation for two family clusters $[37,38]$ and an additional five reports have stated that it could not be ruled out in at least seven families [3, 4, 39-41]. The evidence for person-to-person transmission outside of the family is mixed. In the investigation of the 1997 Hong Kong cases, seropositive healthcare workers were identified, but none have been found in subsequent studies [28, 31, 42] and, as previously mentioned, non-familial clusters are rare. Person-to-person transmission of $\mathrm{A} / \mathrm{H} 5 \mathrm{~N} 1$ clearly can occur but what is perhaps most interesting is the presence of limited intra-familial person-toperson transmission risk but its possible absence in other settings. This could be explained by the special intimacy of familial relationships but alternatively it could be an indicator of a genetic influence on risk; i.e. family members are at increased risk of person-to-person transmission because of a shared genetic susceptibility to infection from any source.

\section{Biological plausibility}

Certain animal species are more susceptible to $\mathrm{H} 5 \mathrm{~N} 1$ than other species and possible factors determining the host-range restriction of avian influenza viruses have been reviewed elsewhere [36, 43, 44]. However, within-species differences also exist and in-bred mice strains exhibit large differences in their susceptibility to influenza infection [7, 45-47]. Indeed, differences in susceptibility of mouse strains to influenza infection, followed by mapping of the mouse disease loci and identification of the region on the human chromosome has led to the identification of the human $M x$ genes involved in response to viral infections [48-50]. 
(a)

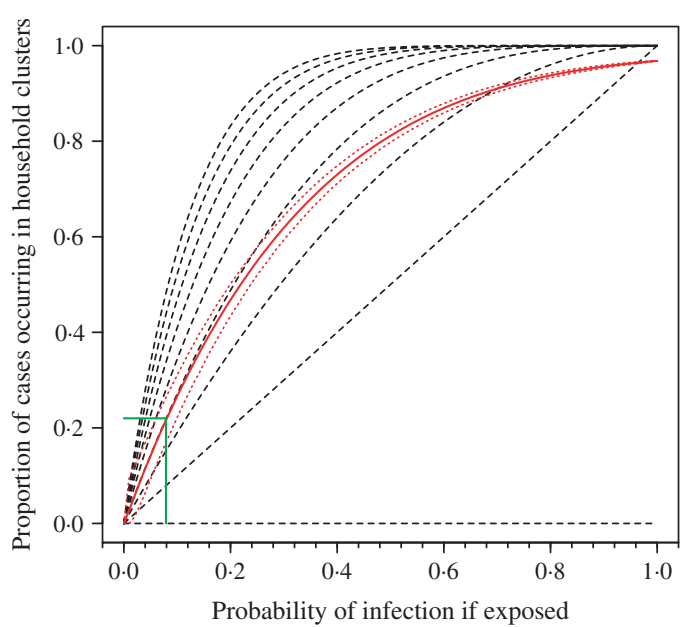

(b)

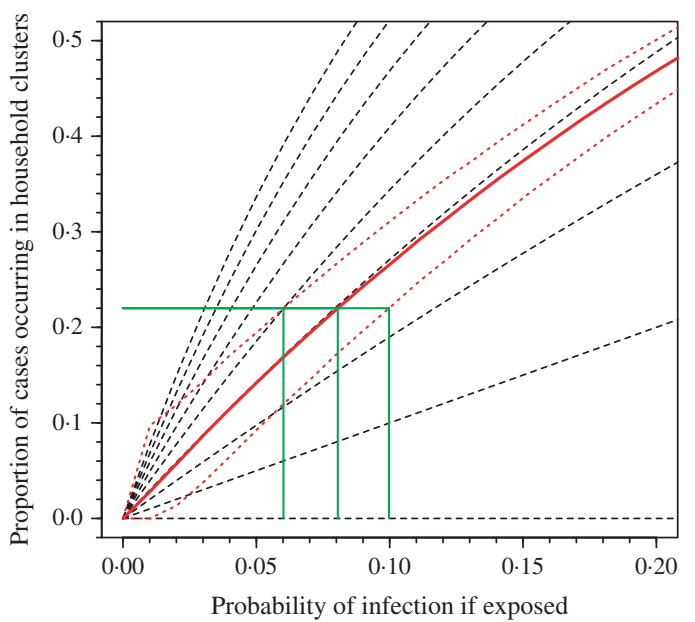

Fig. 2. Proportion of cases occurring in household clusters by probability of infection for different household sizes. (a) All data. (b) Enlargement of left-hand corner of panel ( $a$ ). The broken black lines represent the modelled data for household sizes ranging from nine persons (top) to one person (bottom). The solid red line is the median estimate of the modelled data applying the observed range of household sizes in a Vietnamese cohort. Red dotted lines represent $95 \%$ prediction intervals for 10000 simulations. The solid green lines show the probability of infection compatible with the observed clustering of about 0.22 for median estimate and $95 \%$ prediction intervals of model.

Trammell \& Toth have reviewed possible biological mechanisms of host susceptibility to influenza in the mouse model and similar host genetic influences on susceptibility to infection or disease might also exist in humans [7]. In fact a recent study demonstrated genetic susceptibility to $\mathrm{A} / \mathrm{H} 5 \mathrm{~N} 1$ in mice and called for studies of genetic susceptibility in humans [47]. However, to date no human genetic studies of susceptibility to influenza have been conducted, other than two genealogical studies, one of which identified a heritable predisposition to death from influenza [51, 52].

Candidate host genes that may contribute to severe influenza illness can be proposed a priori from known virus-host interactions critical to infection, replication and pathogenesis [53]. Alternatively, geneexpression profiling using microarrays may provide insights into genes associated with severe disease [54]. The role of cell surface sialic acid receptors in the determination of host specificity of influenza viruses is well documented and therefore the genes encoding these receptors and their associated glycan modifications are potential candidates [55-58]. Cytokine dysregulation has been shown to be a feature of $\mathrm{A} / \mathrm{H} 5 \mathrm{~N} 1$ infection in clinical and animal studies [59-61] and various aspects of innate immunity including collectin-like mannose-binding lectin, tolllike receptors (TLR 3, 7,8), cytokines, chemokines, and interferon-inducible proteins such as $\mathrm{MxA}$ are also plausible candidates [62-68]. Interestingly, susceptibility to other viral respiratory pathogens has been traced to genes of the innate immune system [69-73].

\section{THE CASE AGAINST}

\section{Chance}

Pitzer et al. [6] have argued that the observed pattern of clustering of $\mathrm{A} / \mathrm{H} 5 \mathrm{~N} 1$ cases can be explained by chance and does not provide evidence for a genetic effect. However, the application of similar methods using real data on household structures in Vietnam show that observing $22 \%$ of cases occurring in household clusters is consistent with a risk of infection following exposure of around $8 \%$ (95\% prediction interval 6-10\%) (Fig. 2). If the true risk of infection following exposure were $8 \%$, the current 500 cases would be the result of exposure of only 6250 people globally over the past 5 years. This is an implausibly low number. The number of people exposed is certainly orders of magnitude higher, the risk of infection following exposure substantially lower than $8 \%$ and, therefore, the observation of $22 \%$ household clustering unlikely to be a probable outcome unless other factors are in play. Even if the risk of infection following exposure were $8 \%$, and $22 \%$ of cases occurring in household clusters were 
simply a numerical result of this high risk, in any single affected community we would expect to observe around three sporadic cases for every case occurring in a household cluster $(75 \%$ vs. $25 \%)$. As described above, we actually see few non-familial community clusters. The model of Pitzer et al. also only considered exposure of entire nuclear families with every family member at equal risk. This negates the influence of single or couple households, and occupational exposures outside of the home and therefore over-emphasizes the probability of familial clusters.

\section{Bias}

A key premise is that the observed clustering is a true reflection of the real situation - not simply an apparent pattern caused by biases. It is probable that multiple cases of severe pneumonia in healthy children or adults clustered in time and space are more likely than sporadic cases to be perceived as abnormal and therefore reported to the authorities. It is also true that following a first case which was severely ill or fatal, a second case in a family will rapidly seek medical attention; and indeed several of the reported clusters consist of a first fatality which is clinically suspicious of $\mathrm{H} 5 \mathrm{~N} 1$ and a second laboratoryconfirmed case. So the observed level of clustering could be an artifact of differential ascertainment of clustered vs. sporadic cases. While this bias is bound to be operating to some extent, the question is whether it fully explains the clustering. Moreover, it might be expected that this ascertainment bias would apply similarly to community clusters of genetically unrelated cases as to family clusters.

\section{Confounding}

Familial risk does not necessarily mean genetic risk; families share their homes, food and behaviours with one another and therefore shared 'high-risk' exposures must be a strong contender to explain family clusters. Indeed, the paucity of community clusters of genetically unrelated human H5N1 cases has been suggested to be a reflection of risky behaviours which are unique to the affected families [6]. As noted above, unusual or risky practices have been identified but it has not been possible to attribute many cases to these behaviours since the behaviours are widespread in the community yet absent in many cases. It is certainly possible that behavioural factors partially or completely explain the epidemiological patterns but these have yet to be identified.

The scarcity of human cases despite widespread exposure clearly demonstrates a substantial barrier to humans acquiring infection, and much work has focused on unravelling the genetic and functional characteristics of the viruses which would explain these barriers [74]. There are clear differences between virus strains in their ability to infect and cause severe disease in animal models but the viruses isolated from human cases occurring in family clusters have not been found to be substantially different from viruses causing sporadic human cases or poultry outbreaks [75]. The family clusters have occurred in 11 different countries as a result of infections with five different clades $(0,1,2 \cdot 1,2 \cdot 2,2 \cdot 3)$. So while virus factors are certainly critical in limiting the transmission of influenza $\mathrm{A} / \mathrm{H} 5 \mathrm{~N} 1$ from animals to humans, current data do not allow us to attribute family clustering to viral factors.

\section{CONCLUSION}

The routinely available data on the epidemiology of human cases of $\mathrm{A} / \mathrm{H} 5 \mathrm{~N} 1$ show some unusual patterns to which host genetic susceptibility offers a parsimonious explanation. Of course, this does not mean it is true; but it is both epidemiologically and biologically plausible and worthy of serious investigation. The importance of host genetics in infectious diseases is increasingly being recognized and explored [76-78] and the relationship is usually a complex interaction between the pathogen, environmental influences and a range of innate and adaptive host factors. This poses difficulties for attempts to detect genetic influences on susceptibility to $\mathrm{H} 5 \mathrm{~N} 1$, since very large sample sizes are needed to detect complex or weak effects, yet the total number of cases is very small. However, a host genetics association study may potentially be informative if high-risk genotypes are present. A more powerful strategy would be a genome-wide linkage study in affected families, which could interrogate the whole genome without assuming any prior hypotheses on plausible candidate genes. Given the importance of understanding the key virus-host interactions underlying severe human influenza, a search for such genetic factors in $\mathrm{A} / \mathrm{H} 5 \mathrm{~N} 1$ is worthwhile. However, the scarcity and widespread distribution of human case means that international collaboration is essential to conduct studies of genetic susceptibility to $\mathrm{A} / \mathrm{H} 5 \mathrm{~N} 1$ disease. 


\section{ACKNOWLEDGEMENTS}

The authors thank the following for financial support: Wellcome Trust UK; Genome Institute of Singapore, Agency for Science Technology and Research (A*STAR); National Institutes of Health, South East Asia Infectious Diseases Clinical Research Network. Thanks are also due to Neal Alexander for help with Figure 2.

\section{DECLARATION OF INTEREST}

None.

\section{REFERENCES}

1. van Kerkhove MD, et al. Frequency and patterns of contact with domestic poultry and potential risk of $\mathrm{H} 5 \mathrm{~N} 1$ transmission to humans living in rural Cambodia. Influenza and Other Respiratory Viruses 2008; 2: 155-163.

2. Nguyen TH, Farrar J, Horby P. Person-to-person transmission of influenza A (H5N1). Lancet 2008; 371: 1392-1394.

3. Sedyaningsih ER, et al. Epidemiology of cases of $\mathrm{H} 5 \mathrm{~N} 1$ virus infection in Indonesia, July 2005-June 2006. Journal of Infectious Diseases 2007; 196: 522-527.

4. Kandun IN, et al. Three Indonesian clusters of H5N1 virus infection in 2005. New England Journal of Medicine 2006 ; 355 : 2186-2194.

5. Policy document. Pandemic influenza: science to policy. Policy Document 36/06. London: The Royal Society, 2006.

6. Pitzer VE, et al. Little evidence for genetic susceptibility to influenza A (H5N1) from family clustering data. Emerging Infectious Diseases 2007; 13: 1074-1076.

7. Trammell RA, Toth LA. Genetic susceptibility and resistance to influenza infection and disease in humans and mice. Expert Review of Molecular Diagnostics 2008; 8: 515-529.

8. Olsen SJ, et al. Family clustering of avian influenza A (H5N1). Emerging Infectious Diseases 2005; 11: 1799-1801.

9. Oner AF, et al. Avian influenza A (H5N1) infection in eastern Turkey in 2006. New England Journal of Medicine 2006; 355: 2179-2185.

10. Peiris JS, et al. Re-emergence of fatal human influenza A subtype H5N1 disease. Lancet 2004; 363: 617-619.

11. WHO. Avian influenza - situation in Eygpt - update 10, 2009 (updated 8 April 2009) (http://www.who. int/csr/don/2009_04_08a/en/index.html). Accessed 25 November 2009.

12. Yang Y, et al. Detecting human-to-human transmission of avian influenza A (H5N1). Emerging Infectious Diseases 2007; 13: 1348-1353.

13. WHO. Avian influenza-situation in Indonesiaupdate 16, 2006 (http://www.who.int/csr/don/2006_05_ 31/en/). Accessed 9 May 2009.
14. ECDC. Investigation of the family cluster of human H5N1 cases in North Sumatra, Indonesia, 2006.

15. Chokephaibulkit $\mathbf{K}$, et al. A child with avian influenza A (H5N1) infection. Pediatric Infectious Disease Journal 2005; 24: 162-166.

16. Uiprasertkul M, et al. Apoptosis and pathogenesis of avian influenza A $(\mathrm{H} 5 \mathrm{~N} 1)$ virus in humans. Emerging Infectious Diseases 2007; 13: 708-712.

17. Dinh PN, et al. Risk factors for human infection with avian influenza A H5N1, Vietnam, 2004. Emerging Infectious Diseases 2006; 12: 1841-1847.

18. Areechokchai $\mathbf{D}$, et al. Investigation of avian influenza (H5N1) outbreak in humans-Thailand, 2004. Morbidity and Mortality Weekly Reports 2006; 55 (Suppl. 1): 3-6.

19. Vong S, et al. Low frequency of poultry-tohuman H5NI virus transmission, southern Cambodia, 2005. Emerging Infectious Diseases 2006; 12: 15421547.

20. Abdel-Ghafar AN, et al. Update on avian influenza A (H5N1) virus infection in humans. New England Journal of Medicine 2008; 358: 261-273.

21. Beigel JH, et al. Avian influenza A (H5N1) infection in humans. New England Journal of Medicine 2005; 353: 1374-1385.

22. Yu H, et al. Human influenza A (H5N1) cases, urban areas of People's Republic of China, 20052006. Emerging Infectious Diseases 2007; 13: 10611064 .

23. Thorson A, et al. Is exposure to sick or dead poultry associated with flulike illness?: a population-based study from a rural area in Vietnam with outbreaks of highly pathogenic avian influenza. Archives of Internal Medicine 2006; 166: 119-123.

24. Vong S, et al. Risk factors associated with subclinical human infection with avian influenza A (H5N1) virus - Cambodia, 2006. Journal of Infectious Diseases 2009; 199: 1744-1752.

25. Wang M, Fu CX, Zheng BJ. Antibodies against H5 and $\mathrm{H} 9$ avian influenza among poultry workers in China. New England Journal of Medicine 2009; 360: 2583-2584.

26. Santhia K, et al. Avian influenza A H5N1 infections in Bali Province, Indonesia: a behavioral, virological and seroepidemiological study. Influenza and Other Respiratory Viruses 2009; 3: 81-89.

27. Apisarnthanarak A, et al. Atypical avian influenza (H5N1). Emerging Infectious Diseases 2004; 10: 13211324.

28. Schultsz C, et al. Avian influenza H5N1 and healthcare workers. Emerging Infectious Diseases 2005; 11: 1158-1159.

29. Ortiz JR, et al. Lack of evidence of avian-to-human transmission of avian influenza A (H5N1) virus among poultry workers, Kano, Nigeria, 2006. Journal of Infectious Diseases 2007; 196: 1685-1691.

30. Hinjoy S, et al. Low frequency of infection with avian influenza virus (H5N1) among poultry farmers, Thailand, 2004. Emerging Infectious Diseases 2008; 14: 499-501. 
31. Liem NT, Lim W. Lack of H5N1 avian influenza transmission to hospital employees, Hanoi, 2004. Emerging Infectious Diseases 2005; 11: 210-215.

32. Schultsz C, et al. Prevalence of Antibodies against Avian Influenza A (H5N1) Virus among Cullers and Poultry Workers in Ho Chi Minh City, 2005. PLoS ONE 2009; 4(11): e7948.

33. Dejpichai R, et al. Seroprevalence of antibodies to avian influenza virus A (H5N1) among residents of villages with human cases, Thailand, 2005. Emerging Infectious Diseases 2009; 15: 756-60.

34. Rowe T, et al. Detection of antibody to avian influenza A (H5N1) virus in human serum by using a combination of serologic assays. Journal of Clinical Microbiology 1999; 37: 937-943.

35. Stephenson I, et al. Reproducibility of serologic assays for influenza virus A (H5N1). Emerging Infectious Diseases 2009 ; 15: 1252-1259.

36. Kuiken T, et al. Host species barriers to influenza virus infections. Science 2006; 312: 394-397.

37. Ungchusak K, et al. Probable person-to-person transmission of avian influenza A (H5N1). New England Journal of Medicine 2005; 352: 333-340.

38. Wang H, et al. Probable limited person-to-person transmission of highly pathogenic avian influenza A (H5N1) virus in China. Lancet 2008; 371 : 1427-1434.

39. Katz JM, et al. Antibody response in individuals infected with avian influenza A (H5N1) viruses and detection of anti-H5 antibody among household and social contacts. Journal of Infectious Diseases 1999; 180: 1763-1770.

40. Tran TH, et al. Avian influenza A (H5N1) in 10 patients in Vietnam. New England Journal of Medicine 2004; 350: 1179-1188.

41. Gilsdorf A, et al. Two clusters of human infection with influenza A/H5N1 virus in the Republic of Azerbaijan, February-March 2006. Eurosurveillance 2006; 11(5): $122-126$.

42. Apisarnthanarak A, et al. Seroprevalence of anti-H5 antibody among Thai health care workers after exposure to avian influenza $(\mathrm{H} 5 \mathrm{~N} 1)$ in a tertiary care center. Clinical Infectious Diseases 2005; 40: e16-18.

43. Baigent SJ, McCauley JW. Influenza type A in humans, mammals and birds: determinants of virus virulence, host-range and interspecies transmission. BioEssays 2003 ; 25 : 657-671.

44. Klempner MS, Shapiro DS. Crossing the species barrier - one small step to man, one giant leap to mankind. New England Journal of Medicine 2004; 350: 1171-1172.

45. Srivastava B, et al. Host genetic background strongly influences the response to influenza a virus infections. PLOS ONE 2009; 4: e4857.

46. Salomon $\mathbf{R}$, et al. $\mathrm{Mx} 1$ gene protects mice against the highly lethal human H5N1 influenza virus. Cell Cycle 2007; 6: 2417-2421.

47. Boon AC, et al. Host genetic variation affects resistance to infection with a highly pathogenic $\mathrm{H} 5 \mathrm{~N} 1$ influenza A virus in mice. Journal of Virology 2009; 83: 10417 10426.
48. Staeheli P, et al. Influenza virus-susceptible mice carry Mx genes with a large deletion or a nonsense mutation. Molecular and Cellular Biology 1988; 8: 4518-4523.

49. Haller O, Stertz S, Kochs G. The Mx GTPase family of interferon-induced antiviral proteins. Microbes and Infection 2007; 9: 1636-1643.

50. Haller O, et al. Genetically determined, interferondependent resistance to influenza virus in mice. Journal of Experimental Medicine 1979; 149: 601-612.

51. Albright FS, et al. Evidence for a heritable predisposition to death due to influenza. Journal of Infectious Diseases 2008; 197: 18-24.

52. Gottfredsson M, et al. Lessons from the past: familial aggregation analysis of fatal pandemic influenza (Spanish flu) in Iceland in 1918. Proceedings of the National Academy of Sciences USA 2008; 105: 13031308.

53. Zhang L, et al. Systems-based candidate genes for human response to influenza infection. Infection, Genetics and Evolution 2009; 9: 1148-1157.

54. Pennings JL, Kimman TG, Janssen R. Identification of a common gene expression response in different lung inflammatory diseases in rodents and macaques. PLoS ONE 2008; 3: e2596.

55. Gagneux P, et al. Human-specific regulation of alpha 2-6-linked sialic acids. Journal of Biological Chemistry 2003; 278: 48245-48250.

56. Matrosovich MN, et al. Human and avian influenza viruses target different cell types in cultures of human airway epithelium. Proceedings of the National Academy of Sciences USA 2004; 101 : 4620-4624.

57. Shinya K, et al. Avian flu: influenza virus receptors in the human airway. Nature 2006; 440: 435-436.

58. van Riel D, et al. H5N1 virus attachment to lower respiratory tract. Science 2006; 312: 399.

59. de Jong MD, et al. Fatal outcome of human influenza A (H5N1) is associated with high viral load and hypercytokinemia. Nature Medicine 2006; 12: 1203-1207.

60. Xu T, et al. Acute respiratory distress syndrome induced by avian influenza A (H5N1) virus in mice. American Journal of Respiratory and Critical Care Medicine 2006; 174: 1011-1017.

61. Maines TR, et al. Pathogenesis of emerging avian influenza viruses in mammals and the host innate immune response. Immunological Reviews 2008; 225: 68-84.

62. Tecle $\mathbf{T}$, et al. Inhibition of influenza viral neuraminidase activity by collectins. Archives of Virology 2007; 152: 1731-1742.

63. Tumpey TM, et al. The Mx1 gene protects mice against the pandemic 1918 and highly lethal human H5N1 influenza viruses. Journal of Virology 2007; 81: 1081810821.

64. Szretter KJ, et al. Role of host cytokine responses in the pathogenesis of avian H5N1 influenza viruses in mice. Journal of Virology 2007; 81: 2736-2744.

65. Kash JC, et al. Genomic analysis of increased host immune and cell death responses induced by 1918 influenza virus. Nature 2006; 443 : 578-581. 
66. Dittmann J, et al. Influenza A virus strains differ in sensitivity to the antiviral action of Mx-GTPase. Journal of Virology 2008; 82: 3624-3631.

67. Hidaka F, et al. A missense mutation of the Toll-like receptor 3 gene in a patient with influenza-associated encephalopathy. Clinical Immunology 2006; 119: 188194.

68. Le Goffic R, et al. Cutting edge: influenza A virus activates TLR3-dependent inflammatory and RIGI-dependent antiviral responses in human lung epithelial cells. Journal of Immunology 2007; 178: 3368-3372.

69. Janssen R, et al. Genetic susceptibility to respiratory syncytial virus bronchiolitis is predominantly associated with innate immune genes. Journal of Infectious Diseases 2007; 196: 826-834.

70. Ip WK, et al. Mannose-binding lectin in severe acute respiratory syndrome coronavirus infection. Journal of Infectious Diseases 2005; 191: 1697-1704.

71. Chan VS, et al. Homozygous L-SIGN (CLEC4M) plays a protective role in SARS coronavirus infection. Nature Genetics 2006; 38: 38-46.

72. Hamano E, et al. Polymorphisms of interferoninducible genes OAS-1 and MxA associated with SARS in the Vietnamese population. Biochemical and Biophysical Research Communications 2005; 329: 1234 1239.

73. He J, et al. Association of SARS susceptibility with single nucleic acid polymorphisms of OAS1 and MxA genes: a case-control study. BMC Infectious Diseases 2006; 6: 106.

74. Neumann G, Shinya K, Kawaoka Y. Molecular pathogenesis of $\mathrm{H} 5 \mathrm{~N} 1$ influenza virus infections. Antiviral Therapy $2007 ; 12$ : 617-626.

75. World Health Organization Global Influenza Programme Surveillance Network. Evolution of H5N1 avian influenza viruses in Asia. Emerging Infectious Diseases 2005; 11: 1515-1521.

76. Hill AV. Aspects of genetic susceptibility to human infectious diseases. Annual Review of Genetics 2006; 40 : 469-86.

77. Frodsham AJ, Hill AV. Genetics of infectious diseases. Human Molecular Genetics 2004; 13 (Spec. No. 2): R187-194.

78. Burgner D, Jamieson SE, Blackwell JM. Genetic susceptibility to infectious diseases: big is beautiful, but will bigger be even better? Lancet Infectious Diseases 2006; 6: 653-663. 